\title{
La gestión integrada de recursos hídricos en la regulación de aguas. Identificación y propuesta de avances, a partir de instrumentos vigentes
}

\section{The integrated management of water resources in the regulation of the waters. Identification and advances proposal starting from in force instruments}

Anima este trabajo, la convicción de que la gestión de las aguas ya no se puede atender y resolver, exclusivamente, por medio de los instrumentos jurídicos que provee de manera sólo la legislación de aguas, en especial del Código, lo que se manifiesta sobre todo cuando se trata de implementar una Gestión Integrada de Recursos Hídricos (GIRH). Así, será materia de éste trabajo, la identificación de los aspectos centrales de la GIRH y de su reconocimiento; la caracterización general del régimen unitario de aguas en Chile con análisis de algunas particularidades en zonas específicas; y la
Motivates this work the conviction that the management of water resources cannot be attended and solved exclusively by legal means that provide only a legislation of the waters, specially the Code, this manifests above all when trying to implement an integrated water resources management (IWRM). So, it will be a matter of this work the identification of the central aspects of the IWRM and its recognition; the general caracterization of the unitarian regime of the waters in Chile with the analysis of some particularities in specific zones; and

* Profesor [Asistente] de Derecho Administrativo, Derecho de Aguas y Derecho del Medio Ambiente, de la Universidad Adolfo lbáñez. Dirección Postal: Av. Alberto Hurtado № 750. Viña del Mar, Chile.

Licenciado en Ciencias Jurídicas (1998), U. de Valparaíso; Abogado (2000); Magíster en Ciencia Jurídica (2008) y Doctor en Derecho (2011), P. U. Católica de Chile. Investigador Asociado del Grupo de Regulación de Riesgos y Sectores Estratégicos (GRRISE) de la U. de Barcelona. Correo electrónico: christian.rojas@uai.cl.

Se deja constancia que este trabajo recibió la colaboración de Josefa Asalgado Wilkendorf, Ayudante de Derecho Administrativo de la Facultad de Derecho, Universidad Adolfo lbáñez. Recibido el 1 de octubre de 2018 y aceptado el 21 de noviembre de 2019. 
propuesta de unas bases jurídicas a partir de la regulación vigente para hacer GIRH basada en tres clases de instrumentos jurídicos de relevancia: reglamentos regionales, evaluación ambiental estratégica, y normas de calidad ambiental.

Palabras clave: Gestión, planificación, agua, integración. the proposal of some legal bases starting from the actual regulation to do an IWRM based on three types of relevant legal instruments: regional regulations, strategic environmental assessment and environmental quality standards.

Keywords: Management, planification, water, integrated.

\section{Introducción}

La Gestión Integrada de Recursos Hídricos (GIRH) es un tema que lleva largo tiempo debatiéndose en Chile, y que requiere -conforme la mayoría de los estudios- un conjunto de medidas que reúna forzosamente las tareas que hoy se encuentran divididas en múltiples entes, algunos de carácter estatal y otros de carácter privado. Y lo que se ha sostenido hasta ahora, es que faltan normas para poder hacer eso, pues el Código de Aguas no la contempla.

Lo que pretende este trabajo es sostener lo contrario, pues a lo menos desde el punto normativo, si bien en el Código no hay referencias explícitas, sí pueden verse atisbos de ello implícitamente $y$, junto con otras disposiciones de carácter legal o reglamentario, posibilitaría hoy construir una Gestión Integrada de Recursos Hídricos en Chile.

\section{La Gestión Integrada de Recursos Hídricos, sus fundamentos y reco- nocimiento ${ }^{1}$}

\section{Concepto de GIRH y su fundamento}

En general, la idea de plan y de planificación arranca siempre de la consideración global y conjunta de una determinada realidad. Con el fin de incidir en ella y para alcanzar determinados objetivos, establece las conductas que hay que seguir, precisando también los medios necesarios al efecto. Expresiones, las que han quedado subrayadas, que son las que permiten aproximarnos a una posible categorización del esquema estructural. Al efecto, Martín-Retortillo sostiene que planificación y plan no son conceptos necesariamente coincidentes, de tal manera que todo plan conlleva una determinada actividad o planificación pero se puede planificar no sólo a través de planes. Los objetivos que la planificación postula se pueden alcanzar a través de muy diversas técnicas de acción, como concesiones, autorizaciones, subvenciones, de manera que se acaba afirmando que es imposible tipificar

\footnotetext{
1 Esta parte se basa en el Documento de Trabajo "Diagnóstico y propuestas jurídicas para la gestión integrada de recursos hídricos en la Región de Antofagasta" (inédito), del Comité Técnico de Estudios, Investigación y Política Pública desarrollado por el Instituto de Políticas Públicas (IPP) de la U. Católica del Norte. Se reconoce la tarea de coordinación y recopilación realizada por el Investigador David Espada M.
} 
el fenómeno planificador porque son muchas las figuras o instrumentos que se utilizan para llevarlo a cabo².

Especialmente relevante a nuestros efectos es lo sostenido por Caporena, cuando tratando los fundamentos de la planificación de los recursos hídricos señala que "debido a la íntima relación entre las aguas superficiales, subterráneas, interiores y costeras, la calidad de los recursos hídricos y sus problemas asociados, así como la planificación, tienen que seguir un profeso integrado a nivel de cuenca"3.

Por su parte, Embid Irujo no aconseja realizar un tratamiento unitario de toda la planificación administrativa ya que, dadas las peculiaridades de cada una de las diferentes planificaciones, los resultados son más fructíferos si se profundiza a nivel de cada sector al que responde el fenómeno planificador y el propio concepto de plan, cuyas previsiones, en cualquier caso, se proyectan además durante un tiempo determinado.

De lo dicho, vemos que el plan ha de servir para alcanzar determinados objetivos que se han de delimitar y establecer, de manera tal que el plan como técnica de acción, se establece y legitima para conseguir unos objetivos. Esto afirma el carácter instrumental del plan. Y, por otro lado, la determinación de los objetivos es normalmente una opción política, y entre ellos se ubica la gestión integrada de recursos hídricos; así el plan es el instrumento y la GIRH es el objetivo final; y en este sentido la centralidad de la planificación es crucial para que exista integralidad en la administración de los recursos hídricos.

Luego, Embid Irujo sostiene ${ }^{4}$ que en el ámbito de la moderna política del agua, deben existir dos clases de consensos:

a) Debe existir una Ley de Aguas que contenga el marco jurídico de la utilización y protección del recurso hídrico que la entidad competente deberá aplicar en su labor de gestión.

b) La gestión del agua debe desarrollarse en el marco de una planificación administrativa específica que suele recibir el nombre de Planificación hidrológica.

Y una consecuencia lógica: Uno de los contenidos necesarios de la Ley de Aguas debe ser el relativo a la planificación lo que incluye al menos: a) Especificación de los tipos de Plan (si hay más de uno); b) Sus contenidos; c) Su forma de elaboración y aprobación; y d) Su encaje con la legislación de aguas.

De esta manera el Plan es el instrumento jurídico de la GIRH. Y, por lo mismo, resulta central para una buena gestión de este vital recurso. Así, la funcionalidad que cumple la planificación hidrológica se encuentra en: a) Información sobre recursos hídricos; b) Previsión sobre la utilización y protección

\footnotetext{
2 Martín-Retortillo 1999, 326-327.

3 Caporena, 2014, 337.

4 Embid Irujo 1999, 92-104.
} 
del agua. Consiguiente vinculación a la acción de la Administración hídrica (autorizaciones, concesiones, permisos...); c) Orientación para la realización de futuras inversiones (conexión con la ley de presupuestos); d) Realización efectiva de una política de nexo entre agua, energía y alimentación que solo es posible en el marco de la planificación; y e) Reducción de la discrecionalidad administrativa en la gestión del agua. Y se asoma una clara nueva funcionalidad de la planificación: gestión del riesgo de sequía e inundación.

En consecuencia, los planes de gestión integral de recursos hídricos, por cuenca hidrográfica deben tener una: Descripción de los usos del agua presentes y futuros en su ámbito territorial; Descripción de las necesidades hídricas en cada cuenca; Elementos de preservación del agua para el cumplimiento de los objetivos del plan; Orden de prioridad de los aprovechamientos del agua para actividades productivas, adaptado a las necesidades de la respectiva cuenca; y Descripción de las fuentes de agua y de las áreas de protección hídrica en cada cuenca y los medios de salvaguardarlas ${ }^{5}$.

Otra de las definiciones más divulgadas es la propuesta por la Global Water Partnership (GWP) para quienes la Gestión Integrada de Recursos Hídricos "[e]s un proceso que promueve el manejo y desarrollo coordinado del agua, la tierra y los recursos relacionados, con el fin de maximizar el bienestar social y económico resultante de manera equitativa sin comprometer la sustentabilidad de los ecosistemas vitales"6. A partir de ello, cabe señalar que se trata de un concepto holístico que busca incorporar en la gestión del agua todos aquellos elementos relacionados con ella, haciendo énfasis en la eficiencia económica, la sustentabilidad ambiental y la equidad. Estos últimos se presentan como criterios primordiales en toda la GIRH.

Por medio de la eficiencia económica busca que el agua se use con la máxima eficiencia posible considerando el incremento en la escasez del agua, su fragilidad y vulnerabilidad, además de su creciente demanda. Por medio de la equidad, busca que el derecho básico de todas las personas a acceder a un suministro de agua -en cantidad y calidad suficiente-, sea universalmente reconocido. $Y$ en virtud de la sustentabilidad ambiental se persigue que el uso actual del recurso sea manejado de forma tal que no se deterioren los sistemas de sostenimiento de la vida, pudiendo asegurarse que futuras generaciones puedan hacer uso de este recurso ${ }^{7}$.

De este modo, un enfoque fragmentado tradicional o puramente sectorial ya no es viable ni permite un desarrollo sostenible, y un enfoque más holístico es esencial como medio de superación de las dificultades cada vez más crecientes en este ámbito, a lo cual contribuye la GIRH ${ }^{8}$.

\footnotetext{
Embid Irujo 2012, 85-90. También en Embid IRUjo 2018, 189.

6 Global Water Partnership 2004a, 22.

GWP 2004a, 30.

8 UN Water 2008, 4-5.
} 


\section{Antecedentes y reconocimiento internacional de la GIRH}

Se reconoce a la Conferencia de Naciones Unidas sobre el Agua, celebrada en Mar del Plata entre el 14 y 25 Marzo de 1977, como punto de quiebre en el tratamiento que la comunidad internacional había realizado sobre el agua.

En efecto, antes y después de la Conferencia de Mar del Plata se realizaron otras reuniones que tuvieron por objeto diversos aspectos de la utilización del agua, pero todas ellas tomaron en cuenta el agua como recurso para ser utilizado por un sector específico y no como un elemento natural indispensable que debe ser considerado de manera integrada y comprehensiva. Por el contrario, la Conferencia de Mar del Plata adoptó ese enfoque totalizador o comprensivo que parte por reconocer que el agua no es sólo un bien para ser usado, sino también un bien para ser protegido y cuidadosamente administrado?.

Sin embargo, el origen específico de la GIRH podemos encontrarlo en la Conferencia Internacional sobre el Agua y el Medio Ambiente celebrada en Dublín en 1992, la que fue el primer intento de la comunidad internacional para hacer frente al problema de la escasez del recurso hídrico desde la gestión de las aguas. Como conclusión de esta conferencia, se acordaron los Principios de Dublín sobre el agua y el desarrollo sostenible que establecen: 1) El agua dulce es un recurso finito y vulnerable, esencial para sostener la vida, el desarrollo y el medio ambiente; 2) El aprovechamiento y la gestión del agua debe inspirarse en un planteamiento basado en la participación de los usuarios, los planificadores y los responsables de las decisiones a todos los niveles; 3) La mujer desempeña un papel fundamental en el abastecimiento, la gestión y la protección del agua; y 4) El agua tiene un valor económico en todos sus diversos usos en competencia a los que se destina y debería reconocérsele como un bien económico. Como recomendación para hacer efectivo dichos principios rectores se estableció que "[u]na gestión integrada de las cuencas fluviales ofrece la posibilidad de salvaguardar los ecosistemas acuáticos, y de aportar ventajas a la sociedad sobre una base sostenible".

Luego, en la Conferencia de Naciones Unidas sobre el Medio Ambiente y el Desarrollo celebrada en Río de Janeiro en 1992, estos principios fueron plasmados en el Programa 21 cual establece en su Capítulo 18 una serie de recomendaciones en relación con la gestión integrada del recurso hídrico. En particular el párrafo 18.8. establece que "[l]a ordenación integrada de los recursos hídricos se basa en la percepción de que el agua es parte integrante del ecosistema, un recurso natural y un bien social y bien económico cuya cantidad y calidad determinan la naturaleza de su utilización. Con tal fin, hay que proteger esos recursos, teniendo en cuenta el funcionamiento de los ecosistemas acuáticos y el carácter perenne del recurso con miras a satisfacer y conciliar las necesidades de agua en las actividades humanas. En el aprovechamiento y el uso de los recursos hídricos ha de darse prioridad a la satis-

9 Del Castillo 2009, 23.

ReDAE Revista de Derecho Administrativo Económico, No 30 [julio-diciembre 2019] pp. 141-171 
facción de las necesidades básicas y a la protección de los ecosistemas. Sin embargo, una vez satisfechas esas necesidades los usuarios del agua tienen que pagar unas tarifas adecuadas". Agrega el párrafo 18.9. que "[l]a ordenación integrada de los recursos hídricos, incluida la integración de los aspectos relativos a las tierras y a las aguas, tendría que hacerse a nivel de cuenca o sub-cuenca de captación"10.

Esta preocupación por el desarrollo sustentable y los recursos hídricos fue reafirmada en la Cumbre del Milenio. En efecto, uno de los objetivos de la Declaración del Milenio es "[p]oner fin a la explotación insostenible de los recursos hídricos formulando estrategias de ordenación de esos recursos en los planos regional, nacional y local, que promuevan un acceso equitativo y un abastecimiento adecuado"11.

Posteriormente en la Cumbre Mundial sobre Desarrollo sustentable celebrada en Johannesburgo el 2002, la comunidad internacional adoptó el Plan de Implementación de la Cumbre Mundial sobre Desarrollo Sostenible, con la finalidad de avanzar en la aplicación de la Agenda 21. En virtud de dicho plan los Estados acordaron "[e]laborar planes de gestión integrada y aprovechamiento eficiente de los recursos hídricos para el año 2005, prestando apoyo a los países en desarrollo y adoptando medidas en todos los planos para: 1) Elaborar y aplicar estrategias, planes y programas nacionales y regionales para la ordenación integrada de los ríos, las cuencas hidrográficas y las aguas subterránea"12.

Recientemente en la Cumbre Rio+20 de 2012 se volvieron a reafirmar estos los compromisos para el desarrollo de una GIRH ${ }^{13}$.

Particular importancia para las zonas áridas tiene la Convención de las Naciones Unidas para la Lucha contra la Desertificación ${ }^{14}$, de la cual Chile es parte desde el año $1998^{15}$.

\footnotetext{
10 NAciones UnidAs 1992, 265-266. La Conferencia fue celebrada entre del 3 al 14 de junio en Río de Janeiro. En particular el párrafo 18.11 del Programa 21 establece que "Todos los Estados, según la capacidad y los recursos de que dispongan, y mediante la cooperación bilateral o multilateral, incluidas, según proceda, las Naciones Unidas y otras organizaciones competentes, podrían fijar los objetivos siguientes: a) Para el año 2000: i) Haber elaborado e iniciado programas de acción nacionales con costos y metas determinados, y haber establecido las estructuras institucionales y los instrumentos jurídicos apropiados; ii) Haber establecido programas eficaces de aprovechamiento del agua para lograr sistemas sostenibles de aprovechamiento de los recursos; b) Para el año 2025: i) Haber alcanzado las metas subsectoriales de todas las áreas de programas sobre el agua dulce. Se entiende que el logro de los objetivos cuantificados en los incisos i) y ii) supra dependerá de los recursos financieros nuevos y adicionales que se faciliten a los países en desarrollo de conformidad con las disposiciones pertinentes de la resolución 44/228 de la Asamblea General.

11 Naciones Unidas 2002, 7.

12 lbíd., 23.

13 Naciones Unidas 2012. En particular, UNEP 2012, 106.

14 NACIONES UnIDAS 1994 (4-5, art.1, 11-13 art. 10, 59 anexo).

15 Esta convención entró en vigencia en Chile el 13 de febrero de 1998, a través del Decreto № 2065 del Ministerio de Relaciones Exteriores.
} 
Dicha convención, en su art. $1^{\circ}$ establece que "desertificación" es la degradación de las tierras de zonas áridas, semiáridas y sub-húmedas secas resultante de diversos factores, tales como las variaciones climáticas y las actividades humanas y "lucha contra la desertificación" las actividades que forman parte de un aprovechamiento integrado de la tierra de las zonas áridas, semiáridas y subhúmedas secas para el desarrollo sostenible y que tienen por objeto: 1) la prevención o la reducción de la degradación de las tierras, 2) la rehabilitación de tierras parcialmente degradadas, y 3) la recuperación de tierras desertificadas. En este contexto, el art. $10^{\circ}$ regula los programas de acción nacionales estableciendo que su objeto consiste en determinar cuáles son los factores que contribuyen a la desertificación y las medidas prácticas necesarias para luchar contra la desertificación y mitigar los efectos de la sequía. Particularmente, en relación a América Latina y el Caribe se establece que dichos programas deberán establecer una gestión sostenible de los recursos naturales, en particular el manejo racional de las cuencas hidrográficas (anexo III, Art. $4^{\circ}(d)$ ).

La Organización para la Cooperación y el Desarrollo Económico, en adelante (OCDE), por su parte, aprobó en 2015 los Principios de Gobernanza del Agua de la OCDE donde con una mirada más crítica señalan que la GIRH "ha dado resultados desiguales entre países y dentro de éstos, y requiere de marcos operativos que consideren los aspectos a corto, mediano y largo plazo de una manera coherente y sostenible. A la luz de tales desafíos de implementación, los Principios buscan ayudar a los diferentes órdenes de gobierno a fortalecer la gobernanza del agua para adaptarse a los desafíos del agua actuales y futuros" 16 . Sobre esto, volveremos más adelante.

El establecimiento de una GIRH se presenta así, como una necesidad transversal a otras preocupaciones de la comunidad internacional, principalmente en materia de desarrollo sostenible ${ }^{17}$. Así, por ejemplo, en relación con el cambio climático el Grupo Intergubernamental de Expertos sobre el Cambio Climático (IPCC) ha señalado que la GIRH podría ser un buen instrumento para explorar medidas de adaptación al cambio climático ${ }^{18}$; en relación a la seguridad alimentaria la La Organización de las Naciones Unidas para la Alimentación y la Agricultura (FAO) ha señalado que la seguridad agrícola y alimentaria está íntimamente ligada al agua, y por tanto, las políticas en estas materias deberían de ser consistentes. Las autoridades deben

\footnotetext{
16 OCDE 2015, 3.

17 Sin embargo, no todos ven con buenos ojos la hegemonía internacional de la GIRH en cuanto discurso. Para Mukhtarov y Cherp existen graves peligros en la adopción acrítica de este modelo de gestión del agua a nivel nacional o local. Señalan que la hegemonía del discurso global en relación a GIRH son peligrosas en tres sentidos: 1) privilegia el conocimientos de expertos y científicos como vía de conocimiento (opuesto al conocimiento basado en valores o del conocimiento adquirido con la práctica); 2) denigran la importancia de lo específico y particular en contextos políticos; y 3) incentiva a los actores a adoptar el vocabulario de la gestión integrada y de la participación sin un compromiso real con este, lo que crea dificultades en la supervisión significativa del progreso de la GIRH en los hechos. Mukhtarov F. y Cherp, A. 2014, 17.

18 IPPC 2008, 51-53.
} 
dejar de considerar al agua como un sector económico separado de otros y participar más activamente con otros sectores económicos para enfrentar la escasez de agua en toda su complejidad y, de este modo, hacer que sus estrategias sean coherentes con las decisiones claves que se adoptan en otros sectores. Este diálogo inter-sectorial es esencial para la operación de la $\mathrm{GIRH}^{19}$. En relación con el medio ambiente, el Programa de Naciones Unidas para el Ambiente (UNEP) ha señalado que una GIRH apoya el mantenimiento de caudales ambientales y reservas ecológicas y lo ha incluido como parte de su programa político y estratégico en relación con el agua ${ }^{20}$. Como se puede apreciar la GIRH ha sido reconocida y adoptada por los actores claves en diversas materias sectoriales.

El discurso internacional por una GIRH ha calado fuerte a nivel local, siendo varios los países que han iniciado los procesos para adoptar una gestión integrada y han incorporado expresamente el término "GIRH" en su legislación. Así las cosas, de acuerdo al último reporte de UN-WATER existen aproximadamente 104 países, entre desarrollados y en vías de desarrollo, que están en proceso de adoptar una $\mathrm{GIRH}^{21}$.

Se ha señalado que la implementación de un proceso de GIRH consta de tres pilares fundamentales: i) el avanzar hacia un ambiente propicio de políticas, estrategias y leyes para el desarrollo y la gestión de los recursos hídricos sostenible, ii) el establecer un marco institucional a través del cual las políticas, estrategias y leyes pueden ser implementadas, y iii) la creación de instrumentos de gestión requeridos por estas instituciones para hacer su trabajo ${ }^{22}$.

El monitoreo del cumplimiento de estos pilares ha sido la mayor preocupación de los organismos internacionales relacionados con el agua, principalmente de la UN-WATER. Al efecto, dicho organismo creó en el año 2006 un equipo de trabajo para el monitoreo y reporte de la implementación de la GIRH a nivel local, es decir, de cada lugar donde se requiera a nivel concreto y conforme las características de ese sitio, pues se comprende que metodológicamente es en ese nivel donde se debe realizar el trabajo y seguimiento de esta fórmula de gestión de los recursos hídricos.

El primer reporte que elaboraron fue el Status Report on Integrated Water Resources Management and Water Efficiency Plans (2008) el cual fue preparado para la $16^{\mathrm{a}}$ sesión de la Comisión sobre Desarrollo Sustentable. En 2008, UN-WATER aunó el equipo de trabajo sobre GIRH con el de Monitoreo, lo que dio lugar al Grupo de Trabajo sobre Indicadores Monitoreo e Información; y en esa oportunidad Chile informó que se encontraba preparando los planes para adoptar una GIRH.

\footnotetext{
19 FAO 2008, 60.

20 UNEP 2012.

21 UN-WATER 2008, 53.

22 World Water Assessment Programme 2009, 3-4.
} 
Posteriormente, se elaboró el Status Report on the application of Integrated Approaches to Water Resources Management (2012) para la Conferencia de Desarrollo Sostenible de Naciones Unidas (más conocida como "Rio+20").

En consecuencia, la economía global y la sociedad son dinámicas y el medio ambiente natural también está sujeto a cambios; de modo tal que el sistema de GIRH necesitará, por tanto, ser sensible a los cambios y ser capaz de adaptarse a las nuevas condiciones económicas, sociales y ambientales y a los cambiantes valores humanos ${ }^{23}$.

\section{La concreción de la GIRH a nivel de cuenca}

Conforme lo revisado hasta ahora, la gestión a nivel de cuenca se centra en la aplicación de los principios de la GIRH sobre la base de una mejor coordinación entre los operadores y las entidades administradoras de las aguas a nivel de cuenca, con un enfoque en la asignación y distribuciones confiable y equitativa a quienes dependen del agua.

Se señala que es a nivel de cuenca donde los esquemas de cooperación y los esfuerzos de largo alcance basados en coordinación, colaboración y acciones conjuntas, se implementan actualmente ${ }^{24}$. Así las cosas, la GIRH a nivel de cuenca se ha definido como "un proceso que permite la gestión coordinada del agua, la tierra y los recursos asociados dentro de los límites de una cuenca para optimizar y compartir equitativamente el resultante bienestar socio-económico sin comprometer la salud de ecosistemas vitales a largo plazo" 25 .

Luego, las necesidades de un país por una gestión del recurso hídrico varían de acuerdo a sus características (geografía, clima, tamaño, población, etc.). Ya sea un país o un una cuenca hidrográfica cada área tiene distintos problemas y desafíos en relación con el agua y, por tanto, cada país o cuenca hidrográfica debe plasmar su propia visión y planes de acuerdo a su situación única.

Dentro de las condiciones importantes para la implementación de una GIRH se señalan las siguientes: a) La voluntad política y el compromiso, b) Plan de gestión de cuenca y una visión clara, c) Mecanismos de participación y coordinación, d) El desarrollo de capacidades, e) Un marco jurídico y regulatorio bien definido, f) Planes de asignación del agua, g) Inversión adecuada, estabilidad financiera y una recuperación de costos sustentable, g) Buen conocimiento de los recursos naturales presentes en la cuenca, y h) Un comprensible monitoreo y evaluación ${ }^{26}$.

\footnotetext{
23 GWP 2004b, 12.

24 UNESCO 2009, 2-3.

25 GWP - INBO 2009, 18.

26 UNESCO 2009, 13-18 (donde se indican esos puntos).
} 
Es importante mencionar que no se trata de requisitos previos para la implementación de la GIRH. Como señalamos anteriormente, la GIRH es un proceso y como tal tiene por objeto crear una seguridad hídrica sostenible dentro de las actuales limitaciones a través de una mejora de las condiciones en cada cuenca. Los administradores del agua deben reconocer qué condiciones son esenciales para una gestión efectiva, cuáles no podrán ser establecidas inmediatamente, y cuáles podrán ser desarrolladas total o parcialmente para así avanzar progresivamente en la GIRH.

Por último, los organismos de cuenca proporcionan un buen mecanismo institucional para facilitar la implementación de una GIRH, pues es a nivel de base donde se perciben los cambios en la implementación de mecanismos de mejora.

La aplicación de la GIRH por un organismo de cuenca varía de acuerdo a las condiciones y requerimientos de cada cuenca hidrográfica. Varias cuencas han establecido cuerpos coordinados para facilitar su gestión.

Tal es el caso de la cuenca del Limarí a través del "Sistema Paloma" -hoy la Comunidad de Aguas del Sistema del Embalse Paloma (CASEP)-, que integra a comunidades de agua, asociaciones de canalistas y juntas de vigilancia en un solo gran sistema de administración de los recursos hídricos de la provincia; la cuenca del Elqui agrupados en torno a la Junta de Vigilancia del Río Elqui y sus afluentes que integra de nuevo a todos los usuarios de comunidades de agua, asociaciones de canalistas e incluso a la empresa sanitaria (actualmente Aguas del Valle) en el directorio de dicha organización; y a la Federación de Juntas de Vigilancia de Ríos y esteros de la Sexta Región, que agrupa a seis ríos, tres esteros y dos canales en la región de O’Higgins.

La descentralización y la participación del sector privado ha abierto la vía a la adopción de mecanismos institucionales basados en el concepto de gestión integrada a nivel de cuenca, a través del traspaso de responsabilidades para la gestión de los recursos de los ministerios del gobierno central a los gobiernos locales ${ }^{27}$, a corporaciones públicas autónomas o al sector privado.

\section{Algunas apreciaciones sobre la GIRH y su implementación en Chile}

A este respecto, por lo menos según la organización GWP el caso de Chile es un ejemplo de buenas prácticas en materia de GIRH. Así, tomando de base el agotamiento del agua en las cuencas por el auge de la actividad industrial y la consiguiente competencia entre los distintos sectores por el uso del agua (agrícolas y sanitarios principalmente), valoran que la política chilena en ma-

\footnotetext{
27 Para una propuesta de GIRH a nivel de municipio ver: GWP 2013, 34-35. Señalan a este respecto que "La microcuenca representa el área de drenaje de uno de los afluentes de la cuenca, por nivel puede estar integrada por una base comunitaria y liderada por los municipios [...] El o los municipios o en su caso la mancomunidad de municipios o el Consejo de Cuencas, pueden crear un ambiente propicio, a través de la promulgación de políticas regionales y locales, regulaciones propias y estructuras organizativas, como iniciativas financieras e instrumentos con la gobernabilidad eficaz del agua".
} 
teria de aguas se haya guiado por los mismos principios orientados al mercado que fueron usados para reformar la economía. Señalan que las fuerzas del mercado han jugado un mayor rol en asegurar que el agua sea asignada a un uso de mayor valor. Agregan que el aumento en la inversión privada en saneamiento ha impulsado el desarrollo del sector de alcantarillado, así como el sector de suministro de agua. Concluyen que dichas medidas de GIRH han logrado que Chile apoye el crecimiento de industrias y sectores que demandan agua a la vez que ha logrado un alto crecimiento en las exportaciones ${ }^{28}$.

Como se puede apreciar el enfoque que valora la GWP en relación a la GIRH se vincula más al aspecto económico de la gestión hídrica; en otras palabras, valora el tratamiento que Chile ha realizado del agua como bien económico y el rol asignador del mercado.

En un sentido diverso la opinión de Hantke-Domas quien ha sostenido que "la única legislación que no hace alusión específica y que por el contrario limita estructuralmente la $\mathrm{GIRH}$, es la chilena, en la que son los titulares de los derechos de aprovechamiento quienes son los llamados a gestionar los recursos hídricos al reunirse en organizaciones de usuarios" 29 .

Con todo reconoce alguna planificación pública del desarrollo, asignación, preservación y gestión de los recursos hídricos ${ }^{30}$. Especialmente en relación con las organizaciones de usuarios y a la implementación GIRH a nivel de cuenca, señala que "estas [...] juegan un rol central en la gestión de las aguas, pues son ellas las que regulan el ejercicio de los derechos de aprovechamiento ya sea en cauces superficiales naturales y artificiales, como en aguas subterráneas. Eso sí, nada tienen que ver con la gestión de cuenca, por lo que no se ocupan de otras materias que no sea el uso de los derechos de aguas" ${ }^{\prime 1}$.

Un caso especialmente relevante en materia de GIRH es el de la Junta de Vigilancia del Río Elqui, la que a través del tiempo ha ido desarrollando un modelo de gestión integral ${ }^{32}$.

\footnotetext{
28 GWP 2006, 6.

29 HANTKE-DOMAS 2011, 49.

30 HantKe-Domas 2011, 50. Señala en este sentido que "los principales mecanismos de gestión que son consultados por la legislación chilena son: reserva de caudales ecológicos mínimos; reserva de caudales para uso doméstico; reserva de caudales por razones de interés general (en caso de derechos no consuntivos); remates para reasignación a los privados por no uso; reasignación administrativa y autorizaciones excepcionales en períodos de sequía (por un plazo limitado); obligaciones de sustentabilidad (aguas subterráneas) y establecimiento de restricciones para acceso; instrumentos relativos a la calidad del agua (objetivos de calidad, planes de descontaminación, etc.); planificación de inversión pública de obras hidráulicas; y declaraciones de zonas protegidas.

31 HANTKE-DOMAS 2011, 58-59.

32 La cuenca hidrográfica del río Elqui está ubicada en la Región de Coquimbo; tiene una área de influencia en las comunas de La Serena, Coquimbo, Vicuña y Paihuano, con una población aproximada de 400.000 habitantes; tiene su cabecera en la Cordillera de Los Andes y llega hasta el Océano Pacífico; su superficie aproximada es de $9.600 \mathrm{Km} 2$, correspondiente al $24 \%$ de la re-
} 
Para la administración y explotación de las aguas del río Elqui se encuentra organizada la Junta de Vigilancia, cuya principal misión es la de administrar y distribuir las aguas a que tienen derecho sus miembros en los cauces naturales originados en la cuenca del mencionado río. Además, tiene a su cargo la administración de los embalses La Laguna y Puclaro. La organización ha mostrado una constante preocupación por la educación sobre el tema en las escuelas rurales, y partir del año 2002, inició acciones dirigidas a lograr una gestión integrada de los recursos hídricos del Valle de Elqui, destacándose entre ellas la de impulsar un sistema de administración de los recursos hídricos a través de un contrato de río, modelo basado en la concertación, coordinación y participación de los organismos públicos y privados en el uso del recurso, que entrega la oportunidad para desarrollar una gestión a escala de cuenca hidrográfica, la que actúa bajo los principios de "solidaridad" y "autofinanciamiento", restableciendo el compromiso de los actores locales del agua al incrementar su participación, disminuyendo con ello la toma de decisiones por parte del gobierno central. También a partir del año 2002, está desarrollando un Plan Estratégico que pretende contribuir a una gestión integrada de los recursos hídricos del valle, cuyos objetivos son: Promover la modernización en la gestión y manejo del riego en la cuenca, Fortalecer las organizaciones de regantes, Promover esquemas productivos amigables con el medio ambiente. Generar nuevas alternativas de negocios en beneficio de todos los miembros de la organización, Promover la cultura hídrica en todos los niveles de la población ubicada en la cuenca del río Elqui, e Impulsar un esquema integrado en la gestión de los recursos hídricos del río Elqui a través de un contrato de río.

Luego de ello a través de sucesivas acciones, la Junta de Vigilancia se ha ido afianzando en Chile como muestra de gestión integrada y eficiente a nivel de cuenca ${ }^{33}$.

Ejemplo de ello son el proyecto PROMMRA SIMCA - Elqui "Diseño y puesta en marcha de un sistema de monitoreo de caudales y de un protocolo de determinación de pérdidas de agua, para la priorización de las inversiones público-privadas".

Es una intervención que busca implementar y transferir capacidades para mejorar la gestión de los recursos hídricos disponibles y la eficiencia de la conducción hídrica, mediante una distribución informada y oportuna, y aplicando una metodología de determinación de pérdidas y priorización para las inversiones público-privadas.

El proyecto es financiado con aportes del Fondo de Innovación para la Competitividad del Gobierno Regional de Coquimbo FIC - R 2013, también lo es el proyecto PROMMRA PRO-O.

gión; y la longitud del cauce principal es de aproximadamente $100 \mathrm{Km}$. Además, sus principales afluentes, los ríos Turbio y Claro, tienen longitudes similares (100 km.).

33 Junta de Vigilancia del Río Elqui y sus afLuentes. 
Que persigue que la decisión del manejo de la cuenca a nivel de cauce natural en la cota sobre el embalse, así como la distribución de aguas en base a derechos, se formule a partir de información cuantitativa oportuna y que sea representativa de la diversidad de la cuenca, con el fin de hacer coincidir la decisión de distribución con la información requerida para tomar dicha determinación. Ahora, este proyecto se desarrolla en base a las tres cuencas principales: Elqui, Grande y Limarí y Choapa, en lo que podría considerarse una "exportación" del modelo de GIRH de la Junta de Vigilancia del Río Elqui.

El proyecto presenta como beneficiarios directos, a todos aquellos usuarios de recursos hídricos, que son propietarios de derechos de aprovechamiento de agua tales como: agricultores, industria minera, empresas sanitarias, industria turística, entre otros, de las principales cuencas de los ríos presentes en la región. En calidad de administradores de recursos hídricos: las juntas de vigilancia de los principales ríos de la región (Elqui, Grande y Limarí y Choapa), asociaciones de analistas y comunidades de aguas de las cuencas del Elqui, Limarí y Choapa. También son beneficiarios, indirectos ahora,de este proyecto todas aquellas reparticiones públicas vinculadas con los recursos hídricos y el desarrollo productivo presentes en la región, tales como: Dirección General de Aguas (DGA), Dirección de Obras Hidráulicas (DOH), Comisión Nacional de Riego (CNR) e Instituto de Desarrollo Agropecuario (INDAP), además de investigadores, universidades y centros de investigación nacionales e internacionales ligados al ámbito de los recursos hídricos.

El proyecto es financiado por medio del 2 Fondo de Innovación para la Competitividad (FIC-R) del Gobierno Regional de Coquimbo 2015".

\section{Bases jurídicas para regímenes diferenciados, basados en la GIRH}

\section{La base: principios de la gobernanza del agua de la OCDE}

La posibilidad de adoptar decisiones a nivel regional en una materia sensible como es la regulación y gestión de los recursos hídricos dentro del marco de sus competencias, ha sido un propósito buscado por las autoridades regionales y por las comunidades locales hace ya bastante tiempo. En este apartado, se proponen algunas bases jurídicas que pueden permitir una regulación, aunque marginal, respecto del agua en uno de sus aspectos más esenciales, como es su calidad y su uso sustentable.

El presente apartado abordará someramente el estudio antes señalado de la OCDE, para luego abordar tres instrumentos regionales que pueden permitir la formulación de una política de gestión hídrica dentro del marco del fomento a la protección, conservación y mejoramiento del recurso hídrico en tanto componente ambiental relevante en el ámbito regional y por cuenca.

En efecto, durante el año 2015, la OCDE elaboró un documento en el que propuso los principios relativos a la gobernanza del agua, entendiendo que esta posee determinadas características que lo hacen altamente sensible 
y dependiente de la gobernanza multinivel (nacional, regional y local), dado por factores tales como: i) la vinculación entre diversos sectores, lugares, personas, escalas geográficas y temporales, ii) la preocupación tanto global como local respecto de la gestión del agua dulce (subterránea y superficial), que a la vez involucra diversos actores nacionales y regionales, públicos y privados en el proceso de toma de decisiones, iii) la complejidad de la política del agua, así como su vinculación con objetivos fundamentales para el desarrollo, tales como la salud, el medio ambiente, la agricultura, energía, etc. ${ }^{34}$.

De esta forma, los principios de la gobernanza del agua se justifican en la medida que contribuyen al diseño e implementación de políticas en materia hídrica mediante la responsabilidad compartida entre los distintos órdenes de gobierno, la sociedad civil, las empresas y la amplia gama de actores que juegan un papel en colaboración con los diseñadores de políticas públicas para cosechar los beneficios económicos, sociales y ambientales de la buena gobernanza del agua.

Por su parte, los principios de gobernanza del agua de la OCDE tienen la intención de contribuir a la creación de políticas públicas orientadas a la obtención de resultados ${ }^{35}$, sobre la base de las dimensiones de la gobernanza del agua relativos a la efectividad -esto es, que contribuyan a definir las metas y objetivos sostenibles y claros de la política de agua, a su implementación y la consecución de las metas esperadas-, a la eficiencia-es decir, que maximicen los beneficios de la gestión sostenible del agua y el bienestar, al menor costo para la sociedad-, y a la de confianza y participación -es decir, que contribuyan a crear confianza entre la población, y que garanticen la inclusión de los actores a través de la legitimidad democrática y equidad para la sociedad en general-.

De esta forma, entendemos que en la gestión regional del recurso hídrico se debe tener en cuenta los objetivos de sostenibilidad y sus metas, que permitan a su vez mejorar la calidad de vida de los habitantes de la Región, y que sea participativa a través de los canales más representativos de la región, como es el caso del Gobierno Regional.

La OCDE propone doce principios básicos de gobernanza del agua ${ }^{36}$, de los cuales destacaremos, para los efectos de este informe, los siguientes:

La gestión del agua debe hacerse a escala apropiada dentro del sistema integrado de gobernanza por cuenca para así poder reflejar las condiciones locales, e impulsar la coordinación entre las diferentes escalas (Principio 2).

Debe fomentar la coherencia de políticas a través de una coordinación transversal y eficaz, especialmente entre políticas de agua y medio ambiente,

34 OCDE 2015, 1.

35 Ibíd., 3.

36 OCDE 2015, 8-12 (donde se desarrollan). 
salud, energía, Agricultura, industria, planeamiento y ordenación del territorio (Principio 3).

Se debe asegurar que los marcos regulatorios sólidos de gestión del agua sean implementados y aplicados de manera eficaz en pos del interés público (Principio 7).

Se debe promover la adopción e implementación de prácticas de gobernanza del agua innovadoras entre las autoridades competentes, los órdenes de gobierno y los actores relevantes (Principio 8).

La concreción de estos principios será revisado a través de los siguientes instrumentos jurídicos, plenamente vigentes hoy: reglamentos regionales, evaluación ambiental estratégica de planes y programas, y normas de calidad ambiental relativas al agua según la cuenca que se trate.

Esto, se considera así en este trabajo, posibilitaría contar con mecanismos para definir más o menos específicamente una política de gestión sustentable del agua, de un territorio determinado que reconozca las características propias de cada región.

\section{Reglamentos regionales}

\section{a) Antecedentes}

Un instrumento normativo todavía poco conocido y menos estudiado en nuestra doctrina -con excepción de Ferrada Bórquez y Cordero Quinzacara-, lo constituyen los reglamentos regionales ${ }^{37}$, que tienen su base jurídica en el artículo 113 de la Constitución. En efecto, esta norma le otorga al consejo regional un carácter "normativo, resolutivo y fiscalizador, dentro del ámbito propio de competencia del gobierno regional".

Por su parte, la Ley Orgánica Constitucional de Gobierno y Administración Regional (en adelante LOCGAR) dispone una serie de normas que regulan esta potestad normativa de los consejos regionales. La primera de ellas se encuentra en el artículo 16 letra d), que dispone como funciones generales del gobierno regional "[d]ictar normas de carácter general para regular las materias de su competencia, con sujeción a las disposiciones legales y a los decretos supremos reglamentarios, las que estarán sujetas al trámite de toma de razón por parte de la Contraloría General de la República y se publicarán en el Diario Oficial".

\footnotetext{
37 En general, los reglamentos regionales existen en diferentes clases: 1) los propiamente tales, dictados por los gobiernos regionales en el ámbito de su competencia material que señala la ley y sujeto a las disposiciones reglamentarias emanadas del Presidente de la República; 2) reglamentos internos de organización y funcionamiento del propio Consejo Regional; 3) reglamentos internos de organización de los servicios administrativos del Gobierno Regional; 4) los planes reguladores comunales e intercomunales. En esta parte del informe, nos referiremos solo a los reglamentos regionales propiamente tales. En este sentido FERRADA 2002. También y previamente, con un muy significativo aporte en lo relativo a su competencia material Cordero QuINZACARA 1999, 113-120 (se desarrolla allí la idea).
} 
Luego, el artículo 17 letra d) de la LOCGAR señala entre las atribuciones del Gobierno Regional "fomentar y velar por la protección, conservación y mejoramiento del medio ambiente, adoptando las medidas adecuadas a la realidad de la región, con sujeción a las normas legales y decretos supremos reglamentarios que rijan la materia". En este cometido, el Gobierno puede regular la gestión sustentable del recurso hídrico, dentro del marco de las competencias ambientales de la región, en tanto permite fomentar y velar por la protección, conservación y mejoramiento del medio ambiente.

Por otra parte, una adecuada gestión regional del recurso hídrico no puede entenderse al margen de la planificación territorial, tanto a nivel regional, intercomunal, comunal y seccional, debido al que el uso del territorio incide directamente en el uso sustentable del recurso hídrico.

El artículo 20, a su vez, dispone que para el cumplimiento de sus funciones, el gobierno regional puede aprobar y modificar las normas reglamentarias regionales "que le encomienden las leyes, no pudiendo establecer en ellas, para el ejercicio de actividades, requisitos adicionales a los previstos por las respectivas leyes y los reglamentos supremos que las complementen". Enseguida, el artículo 24 letra f), señala que el Intendente es quien propone al Consejo Regional "los proyectos de reglamentos regionales que regulen materias propias del gobierno regional, en conformidad a las leyes y los reglamentos supremos correspondientes"; funcionario que por su naturaleza es de exclusiva confianza del Presidente de la República.

El artículo 25 inciso $2^{\circ}$, por su parte, entrega al Consejo Regional la atribución para introducir modificaciones a los proyectos de reglamento regional que el Intendente proponga. En este caso, el Intendente "podrá deducir las observaciones que estime pertinentes dentro del término de diez días, acompañando los elementos de juicio que las fundamenten. Transcurrido ese plazo sin que se formulen dichas observaciones, regirá lo sancionado por el consejo. En caso contrario, el consejo solo podrá desecharlas con el voto conforme de la mayoría absoluta más uno de sus miembros en ejercicio".

La normativa descrita, sin embargo, adolece de una serie de dificultades que se traducen en una falta de claridad respecto de su naturaleza y alcances y su relación con las demás normas del ordenamiento jurídico ${ }^{38}$. Sin embargo, y a pesar de que es un instrumento que depende en su iniciativa del Intendente -funcionario de exclusiva confianza del Presidente de la República-, el Consejo Regional puede incidir en su diseño definitivo. Por otra parte, en la perspectiva que el Intendente pueda ser en el futuro elegido mediante sufragio universal, los reglamentos regionales tienen el potencial de ser un poderoso instrumento de política regional en materia de gestión del recurso hídrico.

En este apartado, intentaremos esbozar algunas ideas generales de cómo pueden ser utilizados los reglamentos regionales para abarcar la ges-

38 FerRada 2002, 306. 
tión del recurso hídrico en la región. Para llegar a dicho punto, abordaremos algunas discusiones generales relativas al alcance de la potestad reglamentaria y sus límites.

b) Alcance y límites de la potestad reglamentaria regional

Según se señaló, la potestad reglamentaria descrita se encuentra en el artículo 113 de la Constitución, y en diversas normas de la LOCGAR. En este acápite intentaremos responder a las preguntas relativas a quién ejerce la función, y con qué límites.

Respecto de la primera pregunta, desde el punto de vista constitucional el gobierno de la región se encuentra radicado en el Intendente, quien es funcionario de exclusiva confianza del Presidente de la República, de quien es su representante natural e inmediato. La administración superior de la región, por su parte, está a cargo del gobierno regional, constituido a su vez por el Intendente y el Consejo Regional (artículo 111 de la CPR). De esta forma, la personalidad jurídica -por tanto el titular del poder jurídico de decisión-, le corresponde al Gobierno Regional y no al Consejo Regional, siendo a este último el órgano que le corresponde su ejercicio en el caso concreto de los reglamentos regionales ${ }^{39}$. Esta apreciación puede tener relevancia, dado que la distinción relativa a quien ostenta la facultad y quien la ejerce incide en las potestades que en cada una de las etapas de tramitación del reglamento regional tienen los diversos componentes de Gobierno Regional. Así por ejemplo, llama la atención que sea el Intendente el que, con carácter general, tenga iniciativa en esta potestad, y que el Consejo Regional no tenga iniciativa alguna, salvo en el caso de su reglamento interno ${ }^{40}$.

En cuanto a la segunda pregunta -esto es, los límites de la potestad reglamentaria regional-, se puede destacar el hecho que el ámbito material de los reglamentos regionales es acotado ${ }^{41}$. En efecto, los límites materiales a los reglamentos regionales los podemos encontrar tanto en la Constitución como en la LOCGAR.

En el primer caso, los poderes normativos del Gobierno Regional se encuentran circunscritos al ámbito propio de su competencia, y en el ejercicio de las atribuciones que la LOCGAR le encomiende. De esta forma, las potestades normativas del Gobierno Regional están circunscritas a las funciones y atribuciones establecidas en los artículos 16, 17, 18, 19 y 20 de la LOCGAR, encauzadas dentro del objeto que prevé el artículo 111 de la Constitución para los Gobiernos Regionales, esto es, el desarrollo social, cultural y económico de la región ${ }^{42}$.

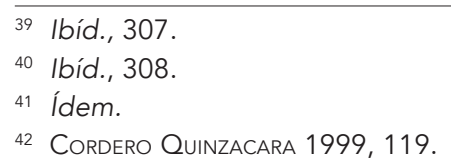


En el segundo caso, las normas que dicte el Gobierno Regional deben sujetarse a las disposiciones legales y a los decretos supremos reglamentarios (artículo 16 letra d) LOCGAR), no pudiendo establecer en ellas, para el ejercicio de actividades, requisitos adicionales a los previstos por las respectivas leyes y los reglamentos supremos que las complementen (artículo 20 LOCGAR).

Un segundo límite material lo encontramos en el artículo 108 de la LOCGAR, que permite reclamar la ilegalidad de un reglamento regional cuando afecta el interés general de la región o de sus habitantes, sin perjuicio de los mecanismos de impugnación ordinarios que se encuentran previstos en la Constitución y en las normas de tipo legal.

Dentro de este marco, la regulación regional del agua se puede circunscribir a la atribución que se le otorga por el artículo 17 letra c) de la LOCGAR, esto es, la función de "fomentar y velar por la protección, conservación y mejoramiento del medio ambiente, adoptando las medidas adecuadas a la realidad de la región, con sujeción a las normas legales y decretos supremos reglamentarios que rijan la materia". Otra norma que puede ser de interés en la formulación de reglamentos regionales es la del artículo 17 letra e) de la LOCGAR, que se refiere a la función de "[f]omentar y propender al desarrollo de áreas rurales y localidades aisladas en la región, procurando la acción multisectorial en la dotación de la infraestructura económica y social".

Una propuesta de esta naturaleza obliga a señalar que la regulación regional del agua debe necesariamente circunscribirse a los aspectos de relevancia ambiental de la misma o de desarrollo rural, y no a los restantes aspectos regulatorios contenidos en la regulación general, dentro del marco de las leyes y decretos supremos reglamentarios ambientales. A su vez, no puede imponer requisitos adicionales al ejercicio de los derechos derivados de la regulación ambiental o de la propia regulación del agua.

Un primer ejemplo de regulación regional que requiere mayor estudio para su efectiva implementación, dice relación con la protección de vegas y bofedales, prevista a nivel nacional en el artículo 58 inciso final del CAg. En efecto, dicha norma señala -con un sentido ambiental-, que "[n]o se podrán efectuar exploraciones en terrenos públicos o privados de zonas que alimenten áreas de vegas y de los llamados bofedales en las Regiones de [Arica y Parinacota], Tarapacá y de Antofagasta, sino con autorización fundada de la [DGA], la que previamente deberá identificar y delimitar dichas zonas". La norma transcrita constituye una forma de protección de las vegas y bofedales, limitando su exploración aguas arriba. Sin embargo, no se hace cargo de lo que ocurre con la exploración aguas abajo de las vegas y bofedales, cuestión que, al menos en principio, puede ser abordada por un reglamento regional con los límites ya indicados previamente.

Un segundo ejemplo lo constituyen las normas relativas a la participación ciudadana. En efecto, de acuerdo a las normas contenidas en la Ley No 18.575 de Bases Generales de la Administración del Estado (según fue 
modificada por la Ley N²0.500 sobre Asociaciones y Participación Ciudadana en la Gestión Pública), los Gobiernos Regionales pueden dictar normas referidas a la participación ciudadana dentro del ámbito regional, en el marco de sus atribuciones, sin discriminación, y sujetos al examen preventivo de legalidad que realiza la Contraloría a través de la toma de razón ${ }^{43}$.

\section{Evaluación Ambiental Estratégica (EAE)}

\section{a) Preliminar}

Un segundo instrumento que puede ser utilizado como una forma de gestionar de una forma sustentable el recurso hídrico lo constituye la Evaluación Ambiental Estratégica (en adelante EAE) a que deben ser sometidos diversos instrumentos de planificación territorial de formulación regional.

La EAE fue incorporada recientemente a la Ley $N^{\circ} 19.300$ por la ley $N^{\circ} 20.417$ que crea el Ministerio de Medio Ambiente, el Servicio de Evaluación Ambiental y la Superintendencia del Medio Ambiente, y se encuentra reglamentado por el Decreto $N^{\circ} 32$ del Ministerio de Medio Ambiente, publicado en el Diario Oficial el 4 de noviembre de 2015.

Conceptualmente, puede ser definida tanto desde un punto de vista formal como material. Desde la primera perspectiva, la Ley $N^{\circ} 19.300$ de Bases Generales del Medio Ambiente (en adelante LBGMA) la define como un "procedimiento realizado por el Ministerio sectorial respectivo, para que se incorporen las consideraciones ambientales del desarrollo sustentable, al proceso de formulación de las políticas y planes de carácter normativo general, que tengan impacto sobre el medio ambiente o la sustentabilidad, de manera que ellas sean integradas en la dictación de la respectiva política y plan, y sus modificaciones sustanciales". Se aclara que la referencia al "Ministerio sectorial respectivo" de la norma, debe referirse a los diversos organismos que habrán de realizar este trámite, como son los Gobiernos Regionales y las Municipalidades, según se verá.

Desde un punto de vista material, la EAE constituye una técnica de planificación coordinada y ajustada en el tiempo, para dar cumplimiento a ciertos objetivos de protección ambiental en materia de planes, políticas o programas, ya sea a nivel nacional, regional o local. Constituye un instrumento destinado a garantizar una coherencia entre los diversos instrumentos de protección ambiental44.

\section{b) Instrumentos que se someten a $E A E$}

La regulación de la EAE se encuentra en el párrafo 1 bis de la LBGMA, que contiene la regla general relativa a los instrumentos que habrán de someterse a evaluación. En este sentido, el artículo $7^{\circ}$ bis señala que deben someterse

\footnotetext{
43 A este respecto, véase el Dictamen N63.805, de 11 de agosto de 2015.

44 BeRMúdez 2014, 197.
} 
a EAE las políticas y planes de carácter normativo general, así como sus modificaciones sustanciales, que tengan impacto sobre el medio ambiente o la sustentabilidad, que el Presidente de la República, a proposición del Consejo de Ministros para la Sustentabilidad, decida ${ }^{45}$.

Sin embargo, el inciso segundo señala que siempre deberán someterse a EAE los siguientes instrumentos: i) los planes regionales de ordenamiento territorial, ii) los planes reguladores intercomunales, iii) planes reguladores comunales, iv) planes seccionales, v) planes regionales de desarrollo urbano, vi) zonificaciones del borde costero, vii) del territorio marítimo, y viii) el manejo integrado de cuencas.

En estos casos, tanto el procedimiento como la aprobación del instrumento estarán a cargo del Ministerio de Vivienda y Urbanismo, del Gobierno Regional o el Municipio o cualquier otro organismo de la administración del Estado, respectivamente.

Las etapas del procedimiento de EAE comprenden tanto el diseño como su aprobación. En la etapa de diseño, el organismo que vaya a dictar la política o plan debe considerar los objetivos y efectos ambientales del instrumento, así como los criterios de desarrollo sustentable del mismo. De acuerdo a lo previsto en el artículo 7 bis de la LBGMA, en esta etapa se debe integrar a otros órganos de la administración del Estado vinculados a las materias objeto de la política o plan, de forma de garantizar una coordinación adecuada.

En la etapa de aprobación, se debe elaborar un informe ambiental, que debe ser remitido al Ministerio de Medio Ambiente para sus observaciones, y luego ser sometido a consulta pública. La LBGMA remite los aspectos procedimentales específicos de la EAE a un reglamento que se encuentra en fase de elaboración. La falta de este reglamento impide que el presente informe pueda referirse a aspectos más específicos de la EAE en esta etapa.

Sin embargo, de acuerdo al artículo $8^{\circ}$ de la ley en comento, una vez evaluados estratégicamente los planes y programas, deben necesariamente ser considerados por los proyectos o actividades sometidos al sistema de evaluación de impacto ambiental, en términos tales que un proyecto o actividad que no considere, o considere de forma inadecuada los planes y programas deberán ser rechazados por la autoridad ambiental correspondiente.

De esta forma, los diversos instrumentos de elaboración y aprobación regional que deben ser sometidos a EAE permiten incorporar mecanismos de gestión integrada del recurso hídrico como parte de una mirada más amplia hacia la planificación territorial, ya sea a nivel regional, comunal o local, incluso en el ámbito de los planes de ordenamiento del borde costero. Una vez incorporado un mecanismo de gestión sustentable del recurso hídrico, los proyectos o actividades que se sometan al sistema de evaluación de impacto

45 No se descarta la incorporación a la EAE de los planes de desarrollo urbano, por ejemplo. 
ambiental deberán considerar dicha gestión, como parte de la evaluación de impacto ambiental que se realice. Como una propuesta concreta, se puede mencionar la gestión sustentable del recurso hídrico tanto en los objetivos como en los criterios de desarrollo sustentable del mismo ${ }^{46}$.

Dentro del marco de los planes y programas señalados en el inciso $2^{\circ}$ del artículo $7^{\circ}$ bis de la LBGMA, los instrumentos con sentido regional más relevantes son el Plan Regional de Ordenamiento Territorial-elaborado por el Gobierno Regional-, los planes reguladores intercomunales -aprobados por el Consejo Regional a propuesta de la Secretaría Regional Ministerial de Vivienda y Urbanismo-, y los planes reguladores comunales, elaborados por cada Municipio. Una adecuada coherencia entre estos instrumentos hacia la gestión del recurso hídrico constituye un valor adicional en su protección.

\section{Normas secundarias de calidad ambiental}

Una tercera alternativa se encuentra en la elaboración de normas de calidad ambiental de los recursos hídricos, en función de la cuenca en que se encuentra.

Desde un punto de vista conceptual, una norma de calidad ambiental es aquélla que establece los valores de las concentraciones y períodos máximos o mínimos permisibles de elementos, compuestos, sustancias, derivados químicos o biológicos, energías, radiaciones, vibraciones, ruidos o combinación de ellos, cuya presencia o carencia en el ambiente pueda constituir un riesgo para la vida o salud de la población, o para la protección o la conservación del medio ambiente, o la preservación de la naturaleza. Si los valores de referencia para la norma de calidad ambiental se fundamentan en la protección de la vida o la salud de la población, se denomina noma primaria de calidad ambiental, en virtud de lo establecido en el artículo $2^{\circ}$ letra n) LBGMA. En el caso que los valores de referencia se fundamentan en la protección del medio ambiente o la preservación de la naturaleza, se denomina norma secundaria de calidad ambiental, de acuerdo a lo dispuesto en el artículo $2^{\circ}$ letra ñ) LBGMA).

En ambos casos, las normas de calidad ambiental se promulgan mediante decreto supremo, que debe llevar la firma del Presidente de la República y del Ministro del Medio Ambiente. En consecuencia, si bien las normas de calidad del agua se dictan a nivel central, tienen sentido regional en tanto son formas de regular los componentes mínimos y máximos del agua a nivel de cuenca, y no a nivel general.

Este ha sido el caso de las normas secundarias de calidad ambiental dictadas para la protección de las aguas continentales superficiales de las cuencas del Río Serrano (Dto. 75 MINSEGPRES, de 19 de marzo de 2010), Lago Llanquihue (Dto. 122 MINSEGPRES, de 4 de junio de 2010), Lago Villarrica

\footnotetext{
${ }^{46}$ Un buen ejemplo de esta referencia puede encontrarse en el Plan Regulador Intercomunal Oasis Andinos.
} 
(Dto. 19 MMA, 16 de octubre de 2013), Río Maipo (Dto. 53 MMA, 4 de julio de 2014), Río Bío Bío (Dto. 9 MMA, 27 de noviembre de 2015), y Río Valdivia (Dto. 1 MMA, 27 de noviembre de 2015).

Si bien en los casos señalados, la regulación ambiental de las aguas se refiere a su variante superficial, nada impide la dictación de una norma de calidad ambiental respecto de aguas subterráneas.

La elaboración de una norma de calidad del agua según la cuenca en la que se encuentre permite: i) contar con un estándar objetivo respecto de la obligación que tiene toda actividad o proyecto que sea desarrollado en las cuencas de la Región respectiva de respetar los niveles exigidos por la norma; ii) contar con estándares objetivos para la posible declaración de zona latente o saturada en los casos que dichas normas sean superadas, adoptando los planes de prevención o de descontaminación en su caso; y iii) establecer si un determinado proyecto o actividad debe ingresar al sistema de evaluación de impacto ambiental bajo la forma de un estudio de impacto ambiental o declaración de impacto ambiental, dado que el criterio de componentes del agua contenidos en la norma de calidad incide en la exigencia del artículo 11 letras a) y b) de la LBGMA ${ }^{47}$.

En consecuencia, la identificación regional de las normas de calidad de aguas no se refiere al órgano del que emana o el órgano que los aprueba, según hemos visto en los instrumentos anteriores, sino que dice relación con los lugares específicamente regulados, esto es las cuencas de la Región de que se trate, tanto las superficiales como las subterráneas.

\section{El paradigma: legislación unitaria frente a situaciones diferentes}

1. La legislación de aguas (en general): inexistencia de regímenes diferenciados

El carácter longitudinal del territorio nacional nos otorga una diversidad de zonas climáticas que varían de norte a sur. Aplicando la clasificación climática de Köppen la zona norte de nuestro país, particularmente la región de Antofagasta se caracteriza por ser una zona climática de marcada aridez (o clima desértico) ${ }^{48}$.

Técnicamente se define zona árida como "aquella región donde la precipitación es usualmente inferior a la evapotranspiración de la vegetación permanente o de los cultivos usuales, entendiendo por ello la cantidad de agua

\footnotetext{
47 Guzmán Rosen 2012, 166.

48 De acuerdo a dicha clasificación (que atiende a la temperatura y a las precipitaciones) la realidad climática de la región de Antofagasta está compuesta mayoritariamente por: 1) Zonas áridas o desértica normal (Baquedano), 2) Zonas áridas muy frías (Calama y San Pedro de Atacama), 3) Zonas áridas con nublados abundantes (Antofagasta), y 4) Frío de Tundra por altura, esta última en menor medida. RIOSECO y TESSER 2006.
} 
que es capaz de evaporar y transpirar cada planta"49. En otras palabras, en estas zonas la evaporación excede la precipitación sobre un promedio anual, de manera que no hay excedente hídrico y no se originan cursos permanentes de agua.

Este carácter árido, que nos distingue de otras zonas del país, no tiene un tratamiento especial o diferencial en el Código de Aguas (en adelante Cag) vigente $^{50}$. En general la actual legislación de aguas no reconoce ni ha reconocido desde la codificación la posibilidad de estatutos diferenciados que atiendan a la diversidad de zonas climáticas que componen nuestro territorio.

La única excepción, particularísima, a esta situación es la que se refiere a la protección de las vegas y bofedales ubicados en las regiones de Arica y Parinacota, Tarapacá y Antofagasta ${ }^{51}$.

Esta aplicación uniforme de legislación de aguas puede encontrar su fundamento en las características propias de los procesos de codificación ${ }^{52}$.

Cabe señalar, sin embargo, que durante del periodo pre-codificador existió un número no menor de normas que tenían un carácter local para la distribución y uso del agua.

En este orden, conviene recordar que, si bien el Código Civil estableció absolutamente y sin excepción de ninguna clase el carácter público de todas las aguas en el artículo 595, en la parte final del párrafo $28^{\circ}$ del Mensaje del mismo se señala respecto de las aguas que se han sentado sólo las bases "reservando los pormenores a ordenanzas especiales, que probablemente no podrán ser unas mismas para las diferentes localidades".

De aquello siguieron las ordenanzas, general primero a partir del 3 de enero de 1872, y luego las especiales que se fueron dictando por cuenca desde la de 17 de enero de 1872 para el río Aconcagua hasta la de 31 de mayo de 1887 de los ríos y esteros del departamento de San Fernando.

\footnotetext{
49 Astaburuaga 2004, 68. Agrega el autor que "[e]n estas zonas el agua es el recurso limitante del desarrollo, tanto económico como urbano, y por lo tanto, cualquier mejoramiento permanente en la eficiencia del uso del agua se traduce en un inmediato aumento proporcional de la productividad de la zona".

50 Aunque se contemplan administrativamente otros mecanismos de limitación al uso del agua en atención a la sequía o escasez, sólo de carácter temporal. Como por ejemplo: decretos de escasez, áreas de restricción, zonas de prohibición, declaración de sitios Ramsar, entre otros

51 Art. 58 inciso final. La norma en comento hace referencia a la región de Tarapacá y Antofagasta, sin embargo, a partir de la modificación territorial establecida por la Ley 20.175 de 8 de octubre de 2007, debemos incluir la región de Arica y Parinacota.

52 El impulso codificador llego tardíamente a la legislación de aguas ya que recién en 1951 vio la luz el primer Código de Aguas de la República. Cabe señalar que el año 1948 fue promulgada la Ley 8.944 que establecía el primer Código de Aguas, sin embargo, tras una serie de críticas en defensa de la propiedad sobre las aguas, su vigencia fue suspendida y se realizaron una serie de modificaciones al proyecto original. Recién el 28 de mayo de 1951, a través de la Ley 9.909 se aprueba el texto definitivo.
} 


\section{Algunas particularidades para regiones o zonas áridas}

\section{a) Antecedentes históricos}

En una variante de reconocimientos particulares, en la región de Antofagasta encontramos el Reglamento de concesiones para usar aguadas de propiedad fiscal en las provincias del Norte (1893), el Reglamento relativo a las mercedes que soliciten en el río Loa y sus afluentes y en las aguadas y vertientes de la provincia de Antofagasta (1913) y su reglamento (1920)53.

Sin embargo, estas normas de carácter local no eran bien vistas por la doctrina nacional, se decía, en este sentido que "la gran cantidad de normas legales dispersas en los más variados textos, hacía sumamente engorroso el estudio del derecho nacional de aguas y su cabal comprensión, e imponía una ímproba y agotadora labor" ${ }^{54}$.

Con todo, también podemos encontrar ciertos atisbos de regulación local durante la época codificadora. Así los códigos de aguas de 1951 y 1969, establecieron normas que repercutían particularmente en la región de Antofagasta.

El primero de ellos regulaba el abastecimiento de ferrocarriles y salitreras (artículo 43), la regulación de las aguas subterráneas (artículo 50-56) y una regulación especial de las mercedes de aguadas en las provincias de Tarapacá y Antofagasta (artículo 58-60). Esta regulación específica "no [era]-como simplemente podría creerse- un estatuto diferencial para dichas regiones sino más bien el intento de resolver solo algunos problemas puntuales" ${ }^{\prime \prime 5}$.

Con todo, dicho regulación establecía que los concesionarios de aguadas en las regiones de Tarapacá y Antofagasta estaban sujetos a ciertas cargas $^{56}$. Estas cargas "[constituían] fuertes limitaciones al derecho de aprovechamiento sobre aguadas, las que reflejan la primigenia valoración de la autoridad de la problemática de la escasez de recurso hídrico en zonas desérticas, que se traducen en medidas tendientes a la racional utilización y distribución de las aguas" ${ }^{57}$. El Código de Aguas de 1969 mantiene, en lo esencial, esta regulación específica en las regiones señaladas.

\footnotetext{
53 Para un análisis histórico de la normativa de aguas en el Norte Chile y en particular en la región de Antofagasta ver: GonzÁlez PIZARRO 1998, 55-63.

54 Vergara Duplaquet 1960, 14.

55 TALA JAPAZ 1999, 182.

56 En este sentido se establece que: 1) Las mercedes de que trata este título pagarán los derechos y gravámenes que fijen las leyes, salvo las que se concedan a las corporaciones de derecho público, que serán gratuitas (art. 59 inciso primero), 2) El concesionario quedará siempre obligado a proporcionar gratuitamente el agua necesaria para los servicios públicos, incluso los ferrocarriles fiscales que se construyan en la región en que se ejerciten las mercedes (art. 59 inciso segundo), 3) El concesionario no podrá impedir a los particulares ni a los establecimientos mineros o de otra naturaleza que existan o puedan existir en las inmediaciones, el uso de las aguas en cuanto las necesiten para la bebida o menesteres domésticos (art. 60).

57 TAla JaPAZ 1999, 190.
} 
Estas sutiles diferenciaciones en la legislación de aguas pueden explicarse por la opción legislativa Mensaje de Código Civil, ya antes señalada.

A pesar de lo anterior, la legislación hídrica actual con el Cag de 1981 presenta un marcado carácter unificador y uniformador. En este sentido "la actual legislación de aguas no asume el carácter longitudinal del territorio nacional [...] que de manera evidente en su recorrido latitudinal cruza distintas zonas climáticas y regiones geográficas muy diferentes que determinan variaciones extremas en temperatura, pluviosidad, regímenes de viento, etc." ${ }^{58}$. En el caso de las regiones con climas áridos, como Antofagasta, esto implica la inexistencia de un tratamiento diferencial que pueda hacer frente a la escasez hídrica de tipo estructural, a la vez que proteja la disponibilidad del recurso hídrico.

\section{b) Situación especial de las vegas y bofedales}

Sin perjuicio de lo señalado, debemos reconocer un atisbo de diferenciación normativa en el Cag que reconocen las características particulares de las zonas áridas, o más bien, las particularidades de la flora y fauna que se desarrolla en dichas zonas. Estamos haciendo referencia a los humedales alto-andinos, más conocidos como vegas y bofedales ${ }^{59}$.

Estos humedales fueron afectados drásticamente por la regulación uniformadora del Cag de 1981. En efecto tras su promulgación la presión sobre los derechos de aprovechamiento de aguas para usos mineros y para agua potable terminó por secar los humedales. Esto ocasionó pérdida de recursos naturales (flora y fauna) y un daño a los derechos ancestrales sobre los recursos naturales de las comunidades indígenas (aymara, quechua y atacameña) ${ }^{60}$.

Para hacer frente a este problema se modificó el Cag en sus artículos 58 y 63. El artículo 58 establece, en su inciso $5^{\circ}$, que no se podrán efectuar exploraciones en terrenos públicos o privados de zonas que alimenten áreas de vegas y de los llamados bofedales en las Regiones de [Arica y Parinacota,] Tarapacá y de Antofagasta, sino con autorización fundada de la DGA, la que previamente deberá identificar y delimitar dichas zonas. Agrega el inciso $3^{\circ}$ del artículo 63 que "las zonas que correspondan a acuíferos que alimenten vegas y los llamados bofedales de las Regiones de [Arica y Parinacota,] Tarapacá y de Antofagasta se entenderán prohibidas para mayores extracciones que las autorizadas, así como para nuevas explotaciones, sin necesidad de

\footnotetext{
58 Boletín 6141-09, sobre exploración, explotación y constitución de derechos de aprovechamiento de aguas, de 7 de octubre de 2008.

59 Las vegas y bofedales son formaciones vegetales que se establecen en un ambiente edáfico, principalmente orgánico, caracterizado por una condición hídrica de saturación permanente, presentando una gran diversidad biológica respecto del entorno y un mayor número de especies vegetales, las cuales son propias de estos sistemas. Estos humedales son zonas de forraje y abrevadero de valiosas especies amenazadas en su conservación (vicuña, guanaco, llama y alpaca entre otros). Alegría y Lillo 2003, 89.

60 ĺdem.
}

ReDAE Revista de Derecho Administrativo Económico, No 30 [julio-diciembre 2019] pp. 141-171 
declaración expresa". Se prohíbe por tanto la exploración y explotación de aguas subterráneas en los acuíferos alimentadores de las vegas y bofedales de las Regiones de Arica y Parinacota, Tarapacá y Antofagasta; zonas que deberán ser previamente identificadas y delimitadas por la DGA.

c) Prohibición de exploración en terrenos públicos o privados de zonas que alimenten áreas de vegas y de los llamados bofedales en las regiones de Arica y Parinacota, Tarapacá y de Antofagasta ${ }^{61}$

La exploración en terrenos públicos o privados en zonas que alimenten áreas de vegas y de bofedales en dichas regiones, sólo puede realizarse con autorización fundada de la DGA, la que previamente deberá identificar y delimitar dichas zonas. Esto según el inciso final del artículo 58 del Cag.

Según el artículo 58 bis "una vez comprobada la existencia de aguas subterráneas en bienes nacionales, el beneficiario del permiso de exploración tendrá la preferencia para que se le otorgue el derecho sobre las aguas alumbradas durante la vigencia del mismo por sobre todo otro peticionario, salvo que otro solicitante, dentro del plazo que señala el inciso primero del [artículo 142 del Cag], haya presentado una solicitud para constituir un derecho de aprovechamiento sobre las mismas aguas que se alumbraron y solicitaron durante la vigencia del período de exploración, en cuyo caso, y si no existe disponibilidad para constituir ambos derechos, se aplicarán las normas sobre remate señaladas en los artículo 142, 143 y 144. Esta excepción no será aplicable si el permiso para explorar aguas subterráneas fue adquirido de conformidad con lo dispuesto en el inciso segundo del artículo 57.

La preferencia consagrada [...], sólo podrá ejercerse dentro del plazo del permiso, y hasta tres meses después, y siempre que el concesionario haya dado cumplimiento a la obligación de presentar un informe completo sobre los trabajos realizados, sus resultados y las conclusiones obtenidas".

En específico, la explotación de aguas subterráneas se encuentra regulado en el artículo 59 y siguientes del Cag.

El artículo 59 señala que "la explotación de aguas subterráneas deberá efectuarse en conformidad a normas generales, previamente establecidas por la [DGA]".

El hecho que la explotación de las aguas subterráneas deba efectuarse en conformidad a las normas generales establecidas por la DGA se ha materializado en sucesivas resoluciones dictada por la autoridad, estableciéndose normas de exploración y explotación de aguas subterráneas, siendo su última versión el Decreto Supremo 203 de 2014, "Reglamento sobre normas de exploración y explotación de aguas subterráneas"62.

\footnotetext{
61 Rojas Calderón 2012, 51. En el mismo sentido, Rojas Calderón 2016, 151-158 (donde se desarrolla la idea).

62 La regulación normativa acerca de la exploración, la explotación y la forma de constitución de derechos de aprovechamiento de aguas subterráneas, así como las formas de limitación (por
} 
A su turno, el artículo 60 regula el procedimiento de constitución una vez comprobada la existencia de aguas subterráneas, el que corresponde al establecido en el Título I del Libro II del Cag. El artículo 61 consagra que la resolución que otorgue el derecho de aprovechamiento de aguas subterráneas, también establece el área de protección en el cual se prohíbe instalar obras similares. Por su parte, el artículo 62 se pone en la hipótesis que la explotación de aguas subterráneas por algunos usuarios ocasione perjuicios a otros titulares de derechos, caso en el que la DGA puede establecer la reducción temporal del ejercicio de los derechos de aprovechamiento.

No obstante lo anterior, es posible reconocer que conforme al artículo 63 del Cag se establece la potestad de la DGA para declarar zonas de prohibición para nuevas explotaciones, mediante resolución fundada en la protección de acuífero, lo que dará origen a una comunidad de aguas formada por todos los usuarios de aguas subterráneas comprendidos en ella.

Sin perjuicio de ello, se establece -por el solo ministerio de la ley- que las zonas que correspondan a acuíferos que alimenten vegas y los llamados bofedales de las Regiones de Arica y Parinacota, Tarapacá y de Antofagasta se entenderán prohibidas para mayores extracciones que las autorizadas, así como para nuevas explotaciones, sin necesidad de declaración expresa, no obstante lo cual la DGA deberá previamente identificar y delimitar dichas zonas $^{63}$. De todos modos la DGA puede alzar la prohibición de explotar, de acuerdo con el procedimiento indicado en el artículo 64, siempre que así lo aconsejen los resultados de nuevas investigaciones respecto de las características del acuífero o la recarga artificial del mismo.

Igualmente, en materia de aguas subterráneas -y siempre considerando que nuestro análisis dice relación con el otorgamiento de derechos de aprovechamiento de aguas-, conforme lo establece el artículo 65, serán áreas de restricción aquellos sectores hidrogeológicos de aprovechamiento común en los que exista el riesgo de grave disminución de un determinado acuífero, con el consiguiente perjuicio de derechos de terceros ya establecidos en él.

Al respecto, cabe señalar que la DGA podrá otorgar provisionalmente derechos de aprovechamiento en aquéllas, limitando prudencialmente los nuevos derechos, pudiendo incluso dejarlos sin efecto en caso de constatar perjuicios a los derechos ya constituidos.

Pues bien, esos derechos "provisionales" podrán transformarse en definitivos, esto en virtud de lo señalado en el artículo 67 del Cag, una vez

medio de áreas de protección o de restricción) están principalmente desarrolladas en dicha resolución, y no en la ley. Ello contraría el tipo de norma usada para regularla, en la medida que ni siquiera es un reglamento, sino una resolución administrativa, lo que es inadmisible desde el punto de vista de la técnica normativa en la medida que en la misma resolución se contienen importantes potestades administrativas que en último término deben sostener su correlato regulatorio en la ley, siquiera de manera general, lo cual no se cumple en esta situación.

63 Rojas Calderón 2012, 51. 
transcurridos cinco años de ejercicio efectivo en los términos concedidos, y siempre que los titulares de derechos ya constituidos no demuestren haber sufrido daños. Lo anterior no será aplicable en el caso del inciso segundo del artículo 66 en que previa autorización de la DGA, cualquier persona puede ejecutar obras para la recarga artificial de acuíferos, teniendo por ello la preferencia para que se le constituya un derecho de aprovechamiento provisional sobre las aguas subterráneas derivadas de tales obras y mientras ellas se mantenga. A estos efectos, la DGA declarará la calidad de derechos definitivos a petición de los interesados y previa comprobación del cumplimiento de las condiciones establecidas.

Todo esto se relaciona con el Decreto Supremo N² 203/2014, Reglamento sobre normas de exploración y explotación de aguas subterráneas, publicado el 7 de marzo del año 2014, que en el artículo $1^{\circ}$ letra a) señala que: "No se podrán efectuar exploraciones en terrenos privados de zonas que alimenten áreas de vegas y de los llamados bofedales de las Regiones de Arica y Parinacota, de Tarapacá y de Antofagasta, sino con autorización fundada de la Dirección General de Aguas, la que previamente deberá identificar y delimitar dichas zonas. La solicitud respectiva deberá ajustarse al procedimiento previsto en el párrafo $1^{\circ}$ del Título I del Libro Segundo del Código de Aguas y a las normas establecidas en el párrafo 2 del Capítulo I de este Reglamento. Será aplicable a estas exploraciones lo dispuesto en el artículo 18 del presente Reglamento".

Por su parte el artículo 18 del reglamento analizado señala: "En la resolución que autorice un permiso de exploración, la Dirección General de Aguas podrá establecer todas aquellas condiciones y medidas contempladas en el presente reglamento y en las demás normas que sean aplicables, para resguardar derechos de aprovechamiento de aguas de terceros, el medio ambiente que dependa de los recursos hídricos y la calidad de las aguas subterráneas contenidas en el acuífero explorado.

Asimismo, dichas condiciones podrán incorporarse durante la exploración mediante resolución fundada que modifique el permiso original.

Sin perjuicio de lo señalado en los incisos anteriores, en aquellos casos en que con la solicitud de exploración debió acompañarse una Resolución de Calificación Ambiental favorable, su aprobación se deberá ajustar a las condiciones y medidas impuestas en ella".

Específicamente, en la región de Antofagasta dichas zonas se encuentran establecidas en la Resolución N 87 de 1 de mayo de 2006 de la DGA. En conformidad con dicha resolución las vegas y bofedales alimentados por zonas acuíferas ascienden a 267.

La protección analizada es un ejemplo claro de regulación específica o diferencial de las aguas que toma en consideración las características particulares de una región -tales como la flora y la fauna-, para establecer el marco regulatorio hídrico al que deberán someterse los particulares. Sin embargo, 
no se trata propiamente de un estatuto diferencial que se hace cargo de las condiciones climáticas de las zonas áridas, sino que más bien "intenta proteger asentamientos humanos de importancia geopolítica, evitar la marginalidad producto de las migraciones hacia sectores urbanos, y preservar el medioambiental evitando que se sequen vegas y bofedales [...]"64.

\section{Conclusiones}

Al finalizar este trabajo, pueden sostenerse las siguientes conclusiones:

1) La GIRH constituye una necesidad no sólo por requerimientos de gestión, sino que también por necesidad jurídica.

Aquello se manifiesta por evidencia empírica, a lo que ha seguido un conjunto de fuentes normativas sobre todo de carácter internacional que la han reconocido, incluido Chile.

2) Hoy, la regulación de aguas tradicional, no recoge o reconoce la necesidad de diferenciación y manejo por cuencas, sino sólo de manera excepcional y sólo a algunas cuestiones. En especial, aquello ocurre en las regiones de Arica-Parinacota, Tarapacá y Antofagasta y a efectos de protección de zonas de vegas y bofedales.

3) De todas maneras, si integramos otros instrumentos más allá de los de la regulación sectorial, puede hacerse. Así es posible hoy implementarla utilizando adecuada y complementariamente los reglamentos regionales, la Evaluación Ambiental Estratégica y las Normas segundarias de calidad ambiental.

4) Por último, en un contexto de regulaciones unitarias y no diferenciadas, la existencia de una regulación específica o diferenciada para las zonas que vegas y bofedales que toma en consideración las características particulares de una región o zona geográfica, para establecer un marco regulatorio hídrico distinto con fines de protección de las personas y del medioambiente, constituye un atisbo reconocido de GIRH vigente en nuestro Derecho.

\section{Bibliografía citada}

Alegría C., María Angélica. y Litlo, Adrián (2003). Protección legal de los humedales alto andino (vegas y bofedales) en Chile. Disponible en: http://biblioteca.cehum.org/bitstream/123456789/539/1/Alegr\%C3\%ADa\%2C\%20Lillo.\%20Protecci\%C3\%B3n\%20 legal\%20de\%20los\%20humedales\%20altoandinos\%20vegas\%20y\%20bofedales\%20 en\%20Chile.pdf [fecha de consulta: 03 octubre 2018].

Astaburuaga, Ricardo (2004). El agua en las zonas áridas de Chile. Disponible en: https:// scielo.conicyt.cl/scielo.php?script=sci_arttext\&pid=S0717-69962004005700018 [fecha de consulta: 14 octubre 2018].

BermúdezZ, Jorge (2014). Fundamentos de Derecho Ambiental. Valparaíso, Ediciones Pontificia Universidad Católica de Valparaíso, 549 pp.

CAPorena, Dante (2014). Principios de Derecho y administración de aguas. Traducción de A. Vergara Blanco, Bogotá, Ediciones Universidad Externado de Colombia, 573 pp.

64 TALA JAPAZ 1999, 190. 
Cordero Quinzacara, Eduardo (1999). La potestad reglamentaria de las entidades territoriales. Los reglamentos regionales, las ordenanzas y los reglamentos municipales. Revista de Derecho de la Universidad Católica del Norte, Año 6, pp. 109-146.

Del Castillo, Lilian (2009). Los foros del agua. De Mar del Plata a Estambul (1977-2009). Disponibles en: www.cari.org.ar [fecha de consulta: 25 noviembre 2015].

EMBID IRUJO, Antonio (1999). La planificación hidrológica en la actualidad. Consideraciones desde una perspectiva jurídica. En Embid Irujo, A. Planificación hidrológica y política hidráulica (El Libro Blanco del Agua), Madrid, Civitas.

Embid Irujo, Antonio (2012). El Derecho de Aguas del siglo XXI. Actas de Derecho de Aguas $\mathrm{N}^{\circ} 2$.

Embid IRUjo, Antonio (2018). El Derecho de Aguas del siglo XXI. En Montenegro, Sergio y otros Coordinadores. Actas de las I Jornadas del Régimen Jurídico de las Aguas. Santiago, Facultad de Derecho, Universidad de Chile-LOM.

Ferrada, Juan Carlos (2002). La Potestad Reglamentaria de los Gobiernos Regionales: Algunas Notas Preliminares. Revista de Derecho de la Universidad Católica de Valparaíso, Vol. XXIII., pp. 305-322.

González PizarRo, José Antonio (1998). Apunte para una reconstrucción de la normativa te las aguas en el norte chileno. Desde el reglamento para el consumo gratuito de agua potable de Antofagasta de 1926 hasta el proyecto de ley sobre agua potable de la provincia de Tarapacá y Antofagasta de 1943. Revista de Derecho de Aguas, Vol. IX, pp. 55-63.

Guzmán Rosen, Rodrigo (2012). Derecho Ambiental Chileno. Santiago, Editorial Planeta Sostenible, $268 \mathrm{pp}$.

HANTKE-DOMAS, Michael (2011). Avances legislativos en gestión sostenible y descentralizada del agua en América Latina. Disponible en: http://repositorio.cepal.org/ [fecha de consulta: 16 noviembre 2015].

MUKHTAROV, Farhad y CHERP, Aleh (2014). The Hegemony of Integrated Water Resources Management as a Global Water Discourse. En: Roy SQuires, Victor, Martin Milner, Hugh, DanielL, Katherine Anne [eds.], River Basin Management in the Twenty-First Century, Australia, CRC Press, $535 \mathrm{pp}$.

Rioseco, Reinaldo / Tesser, Claudio (2006). Cartografía Interactiva de los climas de Chile. Instituto de Geografía. Disponible en: www.uc.cl/sw_educ/geografia/cartografiainteractiva [fecha de consulta: 19 octubre 2015].

Rojas Calderón, Christian (2012). Las potestades administrativas de la Dirección General de aguas. Actas de Derecho de Aguas, № 2, pp. 39-78.

Rojas Calderón, Christian (2016). La distribución de las aguas. Ordenación y servicio público en la Administración Hídrica y en las Juntas de Vigilancia de Ríos. Santiago, Thomson Reuters, 346 pp.

TAla Japaz, Alberto (1999). Derecho de recursos naturales: Ambiente - Aguas - Minas. Santiago, Ediciones Jurídicas La Ley, 382 pp.

Vergara Duplaquet, Ciro (1960). Generalidades. En: Hederra, Ana. [dir.], Comentarios al Código de Aguas. Santiago, Editorial Jurídica de Chile, Tomo I, pp. 1-56.

\section{Otros documentos citados}

GWP - INBO (2009). Manual para la Gestión Integrada de Recursos Hídricos en Cuencas. Disponible en: http://www.gwp.org/ [fecha de consulta: 5 de diciembre 2015].

GWP (2013). Guía para la aplicación de la Gestión Integrada del Recurso Hídrico (GIRH) a nivel municipal. Disponible en: http://www.gwp.org/ [fecha de consulta: 3 diciembre 2015].

GWP (2006). Water and Sustainable Development: Lessons from Chile, Technical Committee, Policy Brief $N^{\circ} 2$. Disponible en: http://www.gwp.org/ [fecha de consulta: 6 diciembre 2015].

Global Water Partnership (2004a). Integrated Water Resources Management, Technical Advisory Committee (TAC), Background Papers N 4. Disponible en: http://www.gwp.org/ [fecha de consulta: 2 diciembre 2015]. 
FAO (2008). Coping with water scarcity. An action framework for agriculture and food security. Disponible en: http://www.fao.org/docrep/016/i3015e/i3015e.pdf [fecha de consulta: 30 noviembre 2015].

instituto de Políticas Públicas (IPP) de la U. Católica del Norte (s/d). Diagnóstico y propuestas jurídicas para la gestión integrada de recursos hídricos en la Región de Antofagasta, Comité Técnico de Estudios, Investigación y Política Pública: en prensa.

IPPC (2008). El cambio climático y el agua. Disponible en: https://www.ipcc.ch/pdf/technical-papers/ccw/climate-change-water-sp.pdf [fecha de consulta: 3 octubre 2018].

Junta de Vigilancia del Rio Eloui y sus afluentes (2019). Proyectos desarrollados. Disponible en http://www.rioelqui.cl/wp_new_site/?page_id=2971 [fecha de consulta: 10 noviembre 2019].

NACIONES UNIDAS (1992). Informe de la Conferencia de Naciones Unidas sobre el medio ambiente y desarrollo (Anexo II), celebrada entre del 3 al 14 de junio en Río de Janeiro.

NACIONES UNIDAS (1994). Convención de las Naciones Unidas de Lucha contra la Desertificación en los Países Afectados por Sequía Grave o Desertificación, en particular en África, de 12 de septiembre de 1994. Esta convención entró en vigencia en Chile el 13 de febrero de 1998 a través del Decreto 2065.

NACIONES UnIDAS (2002). Declaración del Milenio (A/55/L.2), aprobada por la Asamblea General el 13 de septiembre de 2000, párrafo 23.

NACIONES UNIDAS (2002). Informe de la Cumbre Mundial sobre el Desarrollo Sostenible, celebrada en Johannesburgo (A/CONF.199/20) entre el 26 de agosto a 4 de septiembre de 2002, párrafo 26.

NACIONES UNIDAS (2012). Informe de la Conferencia de las Naciones Unidas sobre el DesarroIlo Sostenible, celebrada en Río de Janeiro (A/CONF.216/16) entre el 20 y 22 de junio de 2012, párrafo 120.

OCDE (2015). Principios de Gobernanza del Agua de la OCDE, aprobada por el Consejo Ministerial de la OCDE el 4 de junio de 2015. Disponible en: http://www.oecd.org/ [fecha de consulta: 7 diciembre 2015].

UN-Water (2008). Status Report on Integrated Water Resources Management and Water Efficiency Plans for CSD16. Disponible en: http://www.un.org/ [fecha de consulta: 23 noviembre 2015].

UNEP (2012). The UN-Water Status Report on the Application of Integrated Approaches to Water Resources Management. Disponible en: http://www.un.org/ [fecha de consulta: 28 noviembre 2015].

UNEP (2012). Water policy and strategy of UNEP. Disponible en: http://www.unep.org/ [fecha de consulta: 1 diciembre 2015].

UNESCO (2009): Introduction to the IWRM guidelines at river basin level - Part $1^{\circ}$ - Principles. Disponible en: http://unesdoc.unesco.org/ [fecha de consulta: 3 diciembre 2015].

World Water Assessment Programme (2009). Integrated Water Resources Management UN action. Disponible en: http://unesdoc.unesco.org/ [fecha de consulta: 28 noviembre 2015]. 